\title{
Adolescents with personality disorders suffer from severe psychiatric stigma: evidence from a sample of $|3|$ patients
}

This article was published in the following Dove Press journal:

Adolescent Health, Medicine and Therapeutics

4 May 2015

Number of times this article has been viewed

\author{
Kirsten Catthoor ${ }^{1,3}$ \\ Dine J Feenstra ${ }^{2}$ \\ Joost Hutsebaut ${ }^{2}$ \\ Didier Schrijvers ${ }^{3}$ \\ Bernard Sabbe ${ }^{3}$ \\ 'Department of Psychiatry, \\ Psychiatrisch Ziekenhuis Stuivenberg, \\ ZNA Antwerpen, Antwerp, Belgium; \\ ${ }^{2}$ Viersprong Institute for Studies on \\ Personality Disorders, Halsteren, the \\ Netherlands; ${ }^{3}$ Collaborative Antwerp \\ Psychiatric Research Institute, \\ University of Antwerp, Wilrijk, \\ Belgium
}

Background: The aim of the study is to assess the severity of psychiatric stigma in a sample of personality disordered adolescents in order to evaluate whether differences in stigma can be found in adolescents with different types and severity of personality disorders (PDs). Not only adults but children and adolescents with mental health problems suffer from psychiatric stigma. In contrast to the abundance of research in adult psychiatric samples, stigma in children and adolescents has hardly been investigated. Personality disordered adolescents with fragile identities and self-esteem might be especially prone to feeling stigmatized, an experience which might further shape their identity throughout this critical developmental phase.

Materials and methods: One hundred thirty-one adolescent patients underwent a standard assessment with Axis I and Axis II diagnostic interviews and two stigma instruments, Stigma Consciousness Questionnaire (SCQ) and Perceived Devaluation-Discrimination Questionnaire (PDDQ). Independent sample $t$-tests were used to investigate differences in the mean SCQ and PDDQ total scores for patients with and without a PD. Multiple regression main effect analyses were conducted to explore the impact of the different PDs on level of stigma, as well as comorbid Axis I disorders. Age and sex were also entered in the regression models.

Results and conclusions: Adolescents with severe mental health problems experience a burden of stigma. Personality disordered patients experience more stigma than adolescents with other severe psychiatric Axis I disorders. Borderline PD is the strongest predictor of experiences of stigma. More severely personality disordered adolescents tend to experience the highest level of stigma.

Keywords: labeling, burden of disease, mental health professionals

\section{Introduction}

Not only adults but children and adolescents with mental health problems suffer from psychiatric stigma. ${ }^{1}$ The evidence that the deleterious effects of stigma in adult mental health patients can be applied to children and adolescents with psychiatric problems is abundant. ${ }^{2}$ Findings from psychiatric stigma research in populations with adult patients cannot be generalized to children, adolescents, and their families. ${ }^{1}$

Typically, three major types of psychiatric stigma are distinguished. Public or societal stigma is the extent to which being labeled with a psychiatric diagnosis leads to discriminatory attitudes, devaluation, or rejection. Stigma research focused on minors shows that public stigma is condition-specific. ${ }^{3}$ One study ${ }^{4}$ demonstrated that labeling antisocial behavior in youth as delinquent leads to poorer prognoses. Exactly the same was found regarding the use of the label "sexual abuse" in children. ${ }^{5}$ In the National Study of Stigma in Children, Pescosolido ${ }^{6}$ found that minors with symptoms of attention
Correspondence: Kirsten Catthoor CAPRI, Campus Drie Eiken,

Universiteitsplein I, 2610 Wilrijk, Belgium Tel +32478353957

Email kirstencatthoor@yahoo.com 
deficit hyperactivity disorder or depression were thought to be more dangerous than others with "daily troubles" or asthma. In the same survey, respondents also tended to overestimate the risk of dangerous outbursts in children with depression as compared to adult patients. $^{7}$ In light of our study, it is worth mentioning that adolescents received the most-stigmatizing reactions of all age groups. ${ }^{8}$

Associative stigma is a form of social disapproval because of its direct connection with a stigmatized individual. Associative stigma in children and adolescents is bidirectional. ${ }^{1}$ Parents are directly blamed for the mental disturbance of their children, and the children can be seen as part of a mentally disturbed family. ${ }^{9,10}$ However, Klasen ${ }^{11}$ found that the attribution of a formal diagnosis of attention deficit hyperactivity disorder to a child could relieve guilt and empower parents to seek treatment.

Self-stigma occurs when a labeled person assumes himself or herself to be part of an undesirable group and applies negative stereotypes to himself or herself. ${ }^{12}$ It generates shame, self-directed prejudice, depression, lowered self-esteem, social isolation, and reluctance to seek help. Help-seeking intentions and beliefs about the adequacy of professional mental health sources are influenced by various dimensions of youth stigma. ${ }^{13}$ Moses ${ }^{14}$ found that adolescents hesitate to apply diagnostic labels to themselves and that this is related to their maturing psychological and cognitive development, social context, and desire not to distinguish themselves from normality. Her study suggests that selflabeling in adolescents may be demoralizing, stigmatizing, and disempowering. Therefore, adolescents seem to assess their problems as mental disorders only when they experience them for longer durations of time and after multiple episodes of treatment. In line with these findings, another study by Calear et $\mathrm{al}^{15}$ described the fact that adolescents with features of depression rated their own personal depression stigma as being lower than other people's depression stigma. Moses ${ }^{16}$ reports that the majority of adolescents who were briefly hospitalized for psychiatric reasons showed low levels of stigma apprehension. The subgroups that were vulnerable to higher stigma were young women, those dependent on others for self-worth validation, those with previous experiences with social devaluation, and those with limited sources of identification. Link and Phelan ${ }^{17}$ argue that diagnosis and labeling can be seen as a package deal in terms of stigma. There is evidence that receiving the label of a mental illness is stigmatizing, but it can also be beneficial because it facilitates treatment and ultimately enhances recovery.
There are substantial problems with the use of the concept of self-stigma in children and adolescents because it is unclear in what developmental stage it might occur. ${ }^{2}$ However, there is evidence that adolescents do not differ from adults in terms of their reactions to their own or others' mental disorders. ${ }^{18,19}$ Young teenagers express more anger and less pity toward peers with mental illnesses when they believe they are responsible for their conditions. ${ }^{20}$ Recent literature emphasizes the importance of the awareness of societal stigma as conceptually distinct from personal beliefs or from self-stigma in adults as well as in children and adolescents. ${ }^{21}$ It is important to bear in mind that perceptions of others' beliefs are antecedents of behavior ${ }^{22}$ and that there is evidence for the direct connection between perceived societal stigma and help-seeking. ${ }^{23}$

Recent studies have demonstrated personality disorders (PD) to be a common mental disorder among adolescents, ${ }^{24,25}$ associated with a high burden of disease, ${ }^{24}$ and a range of other problems. ${ }^{26,27}$ Nevertheless, there is a strong hesitation of professionals to diagnose adolescents with a PD. ${ }^{28}$ To our knowledge, no single study exists investigating stigmatization in adolescents with severe personality problems. Some researchers mention the existence of stigma in personality disordered adolescents marginally in their work. ${ }^{29,30}$ Magallón-Neri et al, ${ }^{29}$ for example, draw attention to the possible link between a personality diagnosis in adolescents and its stigmatizing effects in clinical settings. Chanen and McCutcheon ${ }^{30}$ refer to the "diagnosis that dare not speak its name" because of the stigma associated with it. Research on the experience of stigma among adolescents with PD is highly relevant, as such disorders are by definition characterized by problems in self-functioning, including problems in identity, self-esteem, and increased self-blaming. ${ }^{31}$ Adolescents with fragile identities and selfesteem might be especially prone for feeling stigmatized by others, the so-called societal stigma, an experience which might further shape their identity throughout this critical developmental phase.

This study is the first of its kind to investigate stigmatization in a sample of adolescents with serious mental health problems referred for specialized treatment. More specifically, we wanted to test the hypothesis that adolescents with PD might be especially vulnerable for stigma, compared to adolescents suffering from other severe mental disorders in the absence of a PD. Also, we wanted to explore possible difference in experiences of stigmatization among adolescents suffering from different types and levels of severity of PDs. 


\section{Methods}

\section{Participants}

One hundred thirty-three adolescents were consecutively admitted to the inpatient unit of the youth department of Viersprong Institute for Studies on Personality Disorders and enrolled in this study. Viersprong Institute is a highly specialized mental health care institute in the Netherlands, offering outpatient, day hospital, and inpatient psychotherapy for adolescents and adults with severe and complex personality pathology. In general, patients are referred to Viersprong Institute from all over the country because of complex pathology that appears to be refractory to outpatient treatment. All patients underwent a standard assessment as part of the intake procedure, including semistructured interviews to measure Axis I and Axis II disorders and several questionnaires. Interviewers were master-level psychologists who were trained thoroughly. The interviewers received two weekly booster sessions to avoid drifting from the interview guidelines. All patients agreed to participate in the study and gave written informed consent. Two patients did not complete the assessment battery as part of the formal admission procedure, leaving 131 patients for the current sample. The study was approved by the Ethical Commission of the Department of Psychology of the University of Amsterdam.

\section{Measures}

\section{Diagnostic interview}

Anxiety and mood disorders were diagnosed using the Anxiety Disorders Interview Schedule for the Diagnostic and Statistical Manual of Mental Disorders, 4th edition (DSM-IV) Child Version - Child interview (ADIS-C). ${ }^{32,33}$ The ADIS-C is a semistructured interview designed to measure anxiety and other Axis I disorders in children and adolescents. The ADIS-C was supplemented by sections E, G, and $\mathrm{H}$ of the Structured Clinical Interview for DSM-IV Axis I Disorders (SCID-I) $)^{34,35}$ to diagnose substance-related disorders, somatoform disorders, and eating disorders, respectively. The Structured Clinical Interview for DSM-IV Axis II Personality Disorders (SCID-II) ${ }^{36,37}$ was used to diagnose Axis II PDs. Criteria were scored if they were pathological, pervasive, and persistent and whether they were present for 1 year, according to the guideline of the DSM-IV-TR. ${ }^{38}$ Because the DSM-IV-TR does not allow for antisocial PD to be diagnosed in adolescents under the age of 18 , this section was left out of the interview for adolescents under 18. PDs not otherwise specified (NOS) was scored when at least ten PD traits from various disorders were scored without crossing the cutoff point of any formal PD. No interrater reliability data were collected in this study. Previous research has shown ${ }^{39,40}$ that the DSM-IV version of the SCID-II has a good interrater reliability and test-retest interrater reliability for the presence or absence of a PD diagnosis in adults. Although the SCID-II is primarily designed for measuring PDs in adults, previous studies including adolescent samples have shown that the SCID-II is a useful instrument in an adolescent age group. ${ }^{41}$

\section{Stigma measure}

McKeague et al emphasized the lack of a standardized instrument for the assessment of stigma in all its aspects in children and adolescents: "If the stigma associated with mental health problems in childhood and adolescence is to be better understood, then reliable and psychometrically sound instruments for its measurement are needed." ${ }^{21}$ There have been attempts to develop questionnaires to measure public stigma in youngsters, like stereotypes, prejudice, and discrimination. ${ }^{42,43}$ Others focused on stereotypes and desire for social distance from peers with mental health problems. ${ }^{44,45}$ Only a few provided psychometric properties, and none of them was used in populations of adolescent patients. Because no single stigma instrument for children or adolescents was available for the purpose of our study, we were obliged to use adult questionnaires.

The Stigma Consciousness Questionnaire (SCQ) ${ }^{46}$ is used to measure perceived and actual experiences of stereotypes in specific target groups. The instrument is known to represent faithful reflections of stigma experiences. It is a validated instrument, consisting of ten items, scored on a Likert scale, ranging from 1 to 6 : the lower the score, the higher the level of stigma consciousness. A Dutch translation of the questionnaire was used in this study, based on a forward and backward translation. Cronbach's alpha for the SCQ was 0.87 in the study sample.

The Perceived Devaluation-Discrimination Questionnaire $(\mathrm{PDDQ})^{47}$ is used to measure the individual perception of how "most other people" view individuals with mental illness. The scale is widely used in stigma research, ${ }^{48}$ has excellent psychometric properties, and predicts deterioration in self-esteem. It consists of 12 items, rated on a Likert scale, with a range from 1 (highest awareness) to 6 (lowest awareness). A Dutch translation of the questionnaire was used in this study, based on a forward and backward translation. Because of an error in the translation process, one item (question 7) was left out of the version used in our analyses. Cronbach's alpha for the PDDQ was 0.76 in the study sample. 
Table I Mean stigma scores of adolescents with and adolescents without a PD $(n=126-128)^{a}$

\begin{tabular}{|c|c|c|c|c|c|}
\hline Questionnaire & $\begin{array}{l}\text { Patients } \\
\text { with PD } \\
\text { M (SD) } \\
(n=59-60)^{a}\end{array}$ & $\begin{array}{l}\text { Patients } \\
\text { without PD } \\
M(S D) \\
(n=67-68)^{a}\end{array}$ & $t$ & $P$ & $d$ \\
\hline Stigma & $3.82(1.08)$ & $4.48(1.16)$ & 3.337 & 0.001 & 0.59 \\
\hline \multicolumn{6}{|l|}{ Consciousness } \\
\hline \multicolumn{6}{|l|}{ Questionnaire } \\
\hline Perceived & 4.61 (0.79) & $5.05(0.84)$ & 3.046 & 0.003 & 0.54 \\
\hline \multicolumn{6}{|l|}{ Devaluation- } \\
\hline \multicolumn{6}{|l|}{ Discrimination } \\
\hline Questionnaire & & & & & \\
\hline
\end{tabular}

Note: ${ }^{a} n$ varies due to missing values.

Abbreviations: M, mean; PD, personality disorder; SD, standard deviation.

\section{Statistical procedures}

Independent sample $t$-tests were used to investigate differences in the mean total scores for the questionnaires measuring stigma for the patients with and without a PD. Multiple regression main effect analyses were conducted to explore the impact of the different PD diagnosis on level of stigma, as well as comorbid Axis I disorders. Age and sex were also entered in the regression models. To investigate the relation between severity of personality pathology and level of stigma, we observed the trend in stigma scores (for both the SCQ and the PDDQ) with an increasing number of PD traits.

\section{Results}

\section{Participants}

Of the 131 adolescents admitted to the inpatient youth department, $111(84.7 \%)$ were female and 20 were male (16.3\%). Participants were aged $14-19$ years, with a mean age of 16.6 (standard deviation $[\mathrm{SD}]=1.28$ ). As for Axis I disorders, dysthymic disorder was most frequently diagnosed (26.7\%), followed by social phobia (24.4\%), major depressive disorder (12.2\%), posttraumatic stress disorder (9.9\%), and eating disorder NOS (9.2\%). As for the PD, borderline PD was most frequently diagnosed (25.2\%), followed by avoidant PD (16.0\%), and PD NOS (5.3\%). Other PD diagnoses were classified in less than $5 \%$ of the adolescents. Paranoid, schizoid, schizotypal, narcissistic, histrionic, dependent, and passive-aggressive $\mathrm{PD}$ were not diagnosed in this population of adolescents. The mean SCQ score for the total group of patients was $4.17(\mathrm{SD}=1.17)$. The mean PDDQ score was $4.84(\mathrm{SD}=0.84)$.

\section{PD versus no PD}

As depicted in Table 1, adolescents with a PD, unspecified whether there was also an Axis I condition, experienced significantly more stigma than adolescents without a PD, as measured by both the SCQ and the PDDQ.

\section{Stigma by type of PD}

SCQ and PDDQ values for the different PD diagnoses are presented in Tables 2 and 3, respectively. The results presented in both tables suggest that patients with depressive PD experience the highest level of stigma, with mean SCQ and PDDQ scores of 3.24 and 4.42, respectively. The results of the linear regression analyses, however, show that only having a borderline PD significantly predicts a higher level of stigma as measured by the SCQ as well as the PDDQ when controlling for other types of PDs (SCQ: $F[7,120]=2.805, P<0.01$; PDDQ: $F[7,118]=2.180$, $P<0.05)$.

Table 2 Mean SCQ scores for DSM-IV Axis II personality disorders $(n=128)$

\begin{tabular}{|c|c|c|c|c|c|c|}
\hline & \multirow[t]{3}{*}{ n (\%) } & \multirow{3}{*}{$\begin{array}{l}\text { SCQ } \\
M(S D)\end{array}$} & \multicolumn{4}{|l|}{ Analysis } \\
\hline & & & \multirow[t]{2}{*}{ B (SE) } & \multicolumn{2}{|l|}{$\mathrm{Cl}$} & \multirow[t]{2}{*}{$\beta$} \\
\hline & & & & Lower bound & Upper bound & \\
\hline Age & & & $-0.031(0.08)$ & -0.191 & 0.128 & -0.035 \\
\hline Sex & & & $0.556(0.29)$ & -0.022 & 1.133 & 0.170 \\
\hline Borderline PD & $31(24.2)$ & $3.55(1.15)$ & $-0.698(0.24)$ & -1.180 & -0.216 & $-0.256 * *$ \\
\hline Avoidant PD & $21(16.4)$ & $3.98(0.83)$ & $-0.213(0.28)$ & -0.762 & 0.336 & -0.068 \\
\hline Obsessive-compulsive PD & $5(3.9)$ & $3.96(0.72)$ & $-0.167(0.52)$ & -1.187 & 0.853 & -0.028 \\
\hline Depressive PD & $5(3.9)$ & $3.24(0.58)$ & $-0.650(0.53)$ & -1.706 & 0.406 & -0.108 \\
\hline PD NOS & $7(5.5)$ & $4.46(1.19)$ & $0.04 I(0.44)$ & -0.833 & 0.916 & 0.008 \\
\hline Any PD & 60 (46.9) & $3.82(1.08)$ & & & & \\
\hline No PD & $68(53.1)$ & $4.48(1.16)$ & & & & \\
\hline
\end{tabular}

Notes: The sum of the number of patients in the different diagnostic groups is higher than the total number of patients because patients can have more than one personality disorder; $* * P<0.0$ I; $R=0.38$.

Abbreviations: Cl, confidence interval (95\%); DSM-IV, Diagnostic and Statistical Manual of Mental Disorders, 4th edition; M, mean; NOS, not otherwise specified; PD, personality disorder; SCQ, Stigma Consciousness Questionnaire; SD, standard deviation; SE, standard error. 
Table 3 Mean PDDQ scores for DSM-IV Axis II personality disorders $(n=126)$

\begin{tabular}{|c|c|c|c|c|c|c|}
\hline & \multirow[t]{3}{*}{ n (\%) } & \multirow{3}{*}{$\begin{array}{l}\text { PDDQ } \\
\text { M (SD) }\end{array}$} & \multicolumn{4}{|l|}{ Analysis } \\
\hline & & & \multirow[t]{2}{*}{ B (SE) } & \multicolumn{2}{|l|}{ Cl } & \multirow[t]{2}{*}{$\beta$} \\
\hline & & & & Lower bound & Upper bound & \\
\hline Age & & & $0.017(0.06)$ & -0.101 & 0.136 & 0.027 \\
\hline Sex & & & $0.104(0.21)$ & -0.319 & 0.527 & 0.045 \\
\hline Borderline PD & $32(25.4)$ & $4.45(0.80)$ & $-0.523(0.18)$ & -0.871 & -0.175 & $-0.272 * *$ \\
\hline Avoidant PD & $20(15.9)$ & $4.57(0.64)$ & $-0.350(0.21)$ & -0.760 & 0.060 & -0.153 \\
\hline Obsessive-compulsive PD & $5(4.0)$ & $5.28(0.58)$ & $0.443(0.38)$ & -0.301 & 1.188 & 0.103 \\
\hline Depressive PD & $5(4.0)$ & $4.42(0.66)$ & $-0.179(0.39)$ & -0.950 & 0.592 & -0.042 \\
\hline PD NOS & $6(4.8)$ & $5.02(0.74)$ & $0.008(0.35)$ & -0.679 & 0.696 & 0.002 \\
\hline Any PD & $59(46.8)$ & 4.61 (0.79) & & & & \\
\hline No PD & 67 (53.2) & $5.05(0.84)$ & & & & \\
\hline
\end{tabular}

Notes: The sum of the number of patients in the different diagnostic groups is higher than the total number of patients because patients can have more than one personality disorder; $* * P<0.01 ; R=0.34$.

Abbreviations: Cl, confidence interval (95\%); DSM-IV, Diagnostic and Statistical Manual of Mental Disorders, 4th edition; M, mean; NOS, not otherwise specified; PD, personality disorder; PDDQ, Perceived Devaluation-Discrimination Questionnaire; SD, standard deviation; SE, standard error.

\section{Stigma by type of Axis I disorder}

The mean stigma scores for the different Axis I disorders are presented in Tables 4 and 5. When Axis I and Axis II disorders were included in the regression analysis with the SCQ as a measure for stigma, girls and patients with borderline
PD are significant predictors of higher stigma $(F[26,101]$ $=1.634, P<0.05)$. As shown in Table 5, when the PDDQ was used as a measure for stigma, bulimia nervosa, avoidant $\mathrm{PD}$, and borderline PD significantly predicted stigma, with adolescents with bulimia experiencing lower levels of stigma,

Table 4 Mean SCQ scores for Axis I and Axis II disorders $(n=128)$

\begin{tabular}{|c|c|c|c|c|c|c|}
\hline & \multirow[t]{3}{*}{ n (\%) } & \multirow{3}{*}{$\begin{array}{l}\text { SCQ } \\
\text { M (SD) }\end{array}$} & \multicolumn{4}{|l|}{ Analysis } \\
\hline & & & \multirow[t]{2}{*}{ B (SE) } & \multicolumn{2}{|l|}{$\mathbf{C l}$} & \multirow[t]{2}{*}{$\beta$} \\
\hline & & & & Lower bound & Upper bound & \\
\hline Age & & & $-0.034(0.09)$ & -0.209 & 0.141 & -0.037 \\
\hline Sex & & & $0.67 \mid(0.3 I)$ & 0.050 & 1.292 & $0.205^{*}$ \\
\hline Social phobia & $32(25.0)$ & $4.10(1.00)$ & $0.077(0.34)$ & -0.594 & 0.748 & 0.029 \\
\hline Specific phobia & $7(5.5)$ & $4.44(1.10)$ & $0.300(0.49)$ & -0.666 & 1.266 & 0.059 \\
\hline Panic disorder & $2(1.6)$ & $4.95(1.63)$ & $0.408(0.91)$ & -1.394 & 2.211 & 0.043 \\
\hline Agoraphobia & $2(1.6)$ & $3.00(0.57)$ & $-1.668(1.15)$ & -3.958 & 0.622 & -0.177 \\
\hline Generalized anxiety disorder & II (8.6) & $3.78(0.99)$ & $-0.525(0.42)$ & 0.216 & -1.362 & -0.126 \\
\hline Obsessive-compulsive disorder & $8(6.3)$ & $4.75(1.27)$ & $0.606(0.46)$ & -0.298 & 1.510 & 0.126 \\
\hline Posttraumatic stress disorder & $13(10.2)$ & $3.88(0.87)$ & $0.080(0.35)$ & -0.610 & 0.771 & 0.021 \\
\hline Dysthymic disorder & $34(26.6)$ & $4.04(1.20)$ & $-0.214(0.26)$ & -0.718 & 0.291 & -0.081 \\
\hline Major depressive disorder & $16(12.5)$ & $3.83(1.47)$ & $-0.500(0.35)$ & -1.190 & 0.189 & -0.142 \\
\hline Anorexia nervosa & $9(7.0)$ & $4.30(1.12)$ & $0.276(0.4 I)$ & -0.537 & 1.090 & 0.061 \\
\hline Bulimia nervosa & $2(1.6)$ & $4.45(0.07)$ & $0.126(0.8 I)$ & -1.474 & 1.727 & 0.013 \\
\hline Eating disorder NOS & $12(9.4)$ & $3.27(\mathrm{I} .1 \mathrm{I})$ & $-0.679(0.37)$ & -1.416 & 0.057 & -0.170 \\
\hline Conversion disorder & $\mathrm{I}(0.8)$ & $5.30(-)$ & $0.734(1.14)$ & -1.522 & 2.990 & 0.055 \\
\hline Hypochondriasis & $\mathrm{I}(0.8)$ & $3.60(-)$ & $-0.830(1.12)$ & -3.060 & 1.400 & -0.063 \\
\hline Enuresis & $\mathrm{I}(0.8)$ & $3.80(-)$ & $-0.552(1.15)$ & -2.831 & 1.727 & -0.042 \\
\hline Alcohol abuse & $3(2.3)$ & $4.33(0.7 I)$ & $0.543(0.67)$ & -0.786 & 1.871 & 0.070 \\
\hline Alcohol dependence & $\mathrm{I}(0.8)$ & $2.60(-)$ & $1.027(1.70)$ & -2.343 & 4.397 & 0.078 \\
\hline Substance abuse & $\mathrm{I}(0.8)$ & $2.20(-)$ & $-1.686(1.19)$ & -4.055 & 0.682 & -0.127 \\
\hline Substance dependence & $6(4.7)$ & $3.37(0.62)$ & $-0.670(0.53)$ & -1.713 & 0.374 & -0.121 \\
\hline Avoidant PD & $21(16.4)$ & $3.98(0.83)$ & $-0.426(0.36)$ & -1.137 & 0.286 & -0.135 \\
\hline Obsessive-compulsive PD & $5(3.9)$ & $3.96(0.72)$ & $-0.218(0.58)$ & -1.364 & 0.928 & -0.036 \\
\hline Depressive PD & $5(3.9)$ & $3.24(0.58)$ & $-0.405(0.59)$ & -1.577 & 0.767 & -0.685 \\
\hline Borderline PD & $31(24.2)$ & $3.55(1.15)$ & $-0.587(0.26)$ & -1.099 & -0.076 & $-0.216 *$ \\
\hline PD NOS & $7(5.5)$ & $4.46(1.19)$ & $0.065(0.47)$ & -0.861 & 0.991 & 0.013 \\
\hline
\end{tabular}

Notes: The sum of the number of patients in the different diagnostic groups is higher than the total number of patients because patients can have more than one personality disorder; $* P<0.05 ; R=0.54$.

Abbreviations: $\mathrm{Cl}$, confidence interval (95\%); M, mean; NOS, not otherwise specified; PD, personality disorder; SCQ, Stigma Consciousness Questionnaire; SD, standard deviation; SE, standard error. 
Table 5 Mean PDDQ scores for Axis I and Axis II disorders $(n=126)$

\begin{tabular}{|c|c|c|c|c|c|c|}
\hline & \multirow[t]{3}{*}{ n (\%) } & \multirow{3}{*}{$\begin{array}{l}\text { SCQ } \\
M(S D)\end{array}$} & \multicolumn{4}{|l|}{ Analysis } \\
\hline & & & \multirow[t]{2}{*}{ B (SE) } & \multicolumn{2}{|l|}{ Cl } & \multirow[t]{2}{*}{$\beta$} \\
\hline & & & & Lower bound & Upper bound & \\
\hline Age & & & $0.013(0.07)$ & -0.118 & 0.144 & 0.020 \\
\hline Sex & & & $0.221(0.23)$ & -0.236 & 0.678 & 0.094 \\
\hline Social phobia & $30(23.8)$ & $4.74(0.65)$ & $0.005(0.25)$ & -0.496 & 0.505 & 0.002 \\
\hline Specific phobia & $7(5.6)$ & $4.93(0.78)$ & $0.207(0.36)$ & -0.501 & 0.914 & 0.057 \\
\hline Panic disorder & $2(1.6)$ & $5.55(0.78)$ & $0.4 I I(0.66)$ & -0.905 & 1.728 & 0.061 \\
\hline Agoraphobia & $2(1.6)$ & $3.65(0.92)$ & $-0.947(0.84)$ & -2.617 & 0.722 & -0.142 \\
\hline Generalized anxiety disorder & II (8.7) & $4.77(0.79)$ & $-0.207(0.31)$ & -0.825 & 0.411 & -0.070 \\
\hline Obsessive-compulsive disorder & $7(5.6)$ & $5.24(0.59)$ & $0.42(0.36)$ & -0.305 & 1.137 & 0.114 \\
\hline Posttraumatic stress disorder & $13(10.3)$ & $4.58(0.77)$ & $-0.088(0.25)$ & -0.592 & 0.417 & -0.032 \\
\hline Dysthymic disorder & $34(27.0)$ & $4.91(0.83)$ & $0.127(0.19)$ & -0.245 & 0.499 & 0.067 \\
\hline Major depressive disorder & $16(12.7)$ & $4.52(1.00)$ & $-0.417(0.25)$ & -0.921 & 0.086 & -0.166 \\
\hline Anorexia nervosa & $8(6.3)$ & $5.09(0.78)$ & $0.295(0.32)$ & -0.339 & 0.929 & 0.086 \\
\hline Bulimia nervosa & $2(1.6)$ & $5.95(0.21)$ & I.24I (0.59) & 0.071 & 2.411 & $0.185^{*}$ \\
\hline Eating disorder NOS & $12(9.5)$ & $4.48(0.73)$ & $-0.204(0.27)$ & -0.742 & 0.333 & -0.072 \\
\hline Conversion disorder & I $(0.8)$ & $5.60(-)$ & $0.637(0.83)$ & -1.010 & 2.284 & 0.068 \\
\hline Hypochondriasis & $\mathrm{I}(0.8)$ & $4.70(-)$ & $-0.314(0.82)$ & -1.939 & 1.312 & -0.033 \\
\hline Enuresis & $\mathrm{I}(0.8)$ & $4.10(-)$ & $-0.989(0.84)$ & -2.652 & 0.673 & -0.105 \\
\hline Alcohol abuse & $3(2.4)$ & $4.93(0.29)$ & $0.293(0.49)$ & -0.675 & 1.260 & 0.053 \\
\hline Alcohol dependence & $\mathrm{I}(0.8)$ & $3.00(-)$ & $-0.659(1.24)$ & -3.116 & $\mathrm{I} .797$ & -0.070 \\
\hline Substance abuse & $\mathrm{I}(0.8)$ & $4.00(-)$ & $-0.758(0.87)$ & -2.489 & 0.972 & -0.080 \\
\hline Substance dependence & $6(4.8)$ & $4.57(0.90)$ & $0.083(0.38)$ & -0.676 & 0.843 & 0.021 \\
\hline Avoidant PD & $20(15.9)$ & $4.57(0.64)$ & $-0.563(0.27)$ & -1.097 & -0.030 & $-0.246 *$ \\
\hline Obsessive-compulsive PD & $5(4.0)$ & $5.28(0.58)$ & $0.439(0.43)$ & -0.411 & 1.290 & 0.103 \\
\hline Depressive PD & $5(4.0)$ & $4.42(0.66)$ & $0.159(0.43)$ & -0.699 & 1.017 & 0.037 \\
\hline Borderline PD & $32(25.4)$ & $4.45(0.80)$ & $-0.465(0.19)$ & -0.834 & -0.095 & $-0.242 *$ \\
\hline PD NOS & $6(4.8)$ & $5.02(0.74)$ & $0.046(0.36)$ & -0.669 & 0.760 & 0.012 \\
\hline
\end{tabular}

Notes: The sum of the number of patients in the different diagnostic groups is higher than the total number of patients because patients can have more than one personality disorder; $* P<0.05 ; R=0.53$.

Abbreviations: $\mathrm{Cl}$, confidence interval (95\%); M, mean; NOS, not otherwise specified; PD, personality disorder; PDDQ, Perceived Devaluation-Discrimination Questionnaire; SCQ, Stigma Consciousness Questionnaire; SD, standard deviation; SE, standard error.

and adolescents with avoidant or borderline PD experiencing higher levels of stigma $(F[26,99]=1.468, P<0.10)$.

\section{Stigma by comorbidity}

Another regression model investigated the predictive value of having no disorder, only having an Axis I disorder, only having an Axis II disorder, or having both an Axis I and
Axis II disorder on level of stigma. The results in Tables 6 and 7 show that having an Axis I as well as an Axis II disorder was a significant predictor of higher levels of stigma (SCQ: $F[5,122]=3.951, P<0.01$; PDDQ: $F[5,120]=1.982$, $P<0.10)$. As for the results in Table 6, sex was also a significant predictor of higher levels of stigma, with girls experiencing more stigma than boys.

Table 6 Mean SCQ scores by level of comorbidity $(n=128)$

\begin{tabular}{|c|c|c|c|c|c|c|}
\hline & \multirow[t]{3}{*}{ n (\%) } & \multirow{3}{*}{$\begin{array}{l}\text { SCQ } \\
M(S D)\end{array}$} & \multicolumn{4}{|l|}{ Analysis } \\
\hline & & & \multirow[t]{2}{*}{ B (SE) } & \multicolumn{2}{|l|}{$\mathrm{Cl}$} & \multirow[t]{2}{*}{$\beta$} \\
\hline & & & & Lower bound & Upper bound & \\
\hline Age & & & $-0.056(0.08)$ & -0.212 & 0.100 & -0.062 \\
\hline Sex & & & $0.626(0.28)$ & 0.064 & 1.189 & $0.191 *$ \\
\hline Only an Axis I diagnosis & $46(35.9)$ & $4.32(1.20)$ & $-0.485(0.29)$ & -1.054 & 0.084 & -0.200 \\
\hline Only an Axis II diagnosis & $9(7.0)$ & $3.80(1.40)$ & $-0.850(0.45)$ & -1.739 & 0.039 & -0.186 \\
\hline Both an Axis I and an Axis II diagnosis & $51(39.8)$ & $3.82(1.03)$ & $-0.912(0.29)$ & -1.490 & -0.353 & $-0.387 * *$ \\
\hline
\end{tabular}

Notes: $* P<0.05 ; * * P<0.01 ; R=0.37$.

Abbreviations: Cl, confidence interval (95\%); M, mean; SCQ, Stigma Consciousness Questionnaire; SD, standard deviation; SE, standard error. 
Table 7 Mean PDDQ scores by level of comorbidity $(n=126)$

\begin{tabular}{|c|c|c|c|c|c|c|}
\hline & \multirow[t]{3}{*}{ n (\%) } & \multirow{3}{*}{$\begin{array}{l}\text { SCQ } \\
M(S D)\end{array}$} & \multicolumn{4}{|l|}{ Analysis } \\
\hline & & & \multirow[t]{2}{*}{ B (SE) } & \multicolumn{2}{|l|}{ Cl } & \multirow[t]{2}{*}{$\beta$} \\
\hline & & & & Lower bound & Upper bound & \\
\hline Age & & & $0.008(0.06)$ & -0.109 & 0.125 & 0.013 \\
\hline Sex & & & $0.1 I I(0.2 I)$ & -0.308 & 0.530 & 0.048 \\
\hline Only an Axis I diagnosis & $45(35.7)$ & $5.00(0.86)$ & $-0.138(0.22)$ & 0.287 & 0.143 & -0.079 \\
\hline Only an Axis II diagnosis & $9(7.1)$ & $4.53(0.86)$ & $-0.593(0.33)$ & -1.255 & 0.068 & -0.183 \\
\hline Both an Axis I and an Axis II diagnosis & $50(39.7)$ & $4.62(0.78)$ & $-0.517(0.21)$ & $-0.94 \mid$ & -0.093 & $-0.302 *$ \\
\hline
\end{tabular}

Notes: $* P<0.05 ; R=0.28$.

Abbreviations: $\mathrm{Cl}$, confidence interval (95\%); M, mean; PDDQ, Perceived Devaluation-Discrimination Questionnaire; SCQ, Stigma Consciousness Questionnaire; SD, standard deviation; SE, standard error.

\section{Stigma by severity of personality pathology}

Table 8 shows that the perceived level of stigma in general is associated with severity of personality pathology, as measured by the total number of PD traits. However, these differences were not statistically significant.

\section{Discussion}

To our knowledge, this is the first study that explores the experience of stigma among adolescents with PDs. Our study demonstrates that 1) treatment-seeking adolescents with severe mental health problems experience a high burden of stigma; 2) treatment-seeking adolescents with PDs experience more stigma than treatment-seeking adolescents with other severe and treatment refractory psychiatric Axis I disorders; 3) borderline PD is the strongest predictor of experiences of stigma, when controlled for other types of personality pathology; and 4) more severely personality disordered adolescents - as measured by the number of PD traits - tend to experience the highest levels of stigma. Taken together, these findings highlight the importance of stigmatization

Table 8 SCQ and PDDQ scores by total number of personality disorder traits $(n=126-128)^{a}$

\begin{tabular}{|c|c|c|c|c|c|}
\hline & \multirow{2}{*}{$\begin{array}{l}\text { Number of } \\
\text { PD traits }\end{array}$} & \multicolumn{2}{|c|}{ SCQ } & \multicolumn{2}{|c|}{ PDDQ } \\
\hline & & $M$ & SD & $M$ & SD \\
\hline $\begin{array}{l}\text { Category I } \\
(n=4 I)\end{array}$ & $0-4$ & 4.49 & 1.17 & 5.02 & 0.92 \\
\hline $\begin{array}{l}\text { Category } 2 \\
(\mathrm{n}=6 \mathrm{I}-62)^{\mathrm{a}}\end{array}$ & $5-9$ & 4.18 & 1.13 & 4.86 & 0.78 \\
\hline $\begin{array}{l}\text { Category } 3 \\
(\mathrm{n}=20-2 \mathrm{I})^{\mathrm{a}}\end{array}$ & $10-14$ & 3.63 & 1.21 & 4.48 & 0.83 \\
\hline $\begin{array}{l}\text { Category } 4 \\
(n=4)\end{array}$ & $15+$ & 3.60 & 0.56 & 4.63 & 0.41 \\
\hline
\end{tabular}

Note: ${ }^{a} n$ varies due to missing values.

Abbreviations: M, mean; PD, personality disorder; PDDQ, Perceived DevaluationDiscrimination Questionnaire; SCQ, Stigma Consciousness Questionnaire; SD, standard deviation. among adolescents suffering from PDs, with more severely disordered - and more specifically, borderline PD - patients experiencing the highest level of stigma.

There might be several reasons why these adolescents experience higher stigma, even before they were officially diagnosed and thus labeled. First of all, these youngsters often lack a unique sense of self, clearly delineated from others, making them extra vulnerable for incorporating negative critique on their behavioral and emotional problems. Because their identity depends upon definitions given by others, negative interactions affect them more intensely and might give the impression of being prejudiced. Second, lifelong patterns of difficulties at home and at school, the confrontation with being troublesome and difficult in interpersonal relationships, can lead to feelings of social exclusion and discrimination. All these arguments point into the direction of substantial societal stigma, comparable to other condition-specific stigma in previous research. ${ }^{6-8}$ It remains unclear whether this higher societal stigma in personality disordered patients is due to the externalizing symptomatology or due to the identity of having mental health problems. In any case, warranty is needed to prevent these adolescents from dropping out from treatment, as proven in other studies. ${ }^{13}$

This study has some restrictions that should be stressed. Results could be biased by the disequilibrium between male and female participants, although previous research has proven substantial vulnerability for stigma in girls. ${ }^{16}$ Besides, participants were treatment-seeking adolescents that were referred to a specialized mental health care setting after, often, several years of treatment elsewhere. Part of the experience of stigmatization might be due to an unhelpful treatment trajectory instead of the PD per se. More research with untreated and newly developed PDs could shed light on the question of whether the stigma is intrinsic to PDs or is an adverse outcome of a long duration of illness. This study includes only limited categories of PDs, with a majority 
of patients with borderline PD, making it difficult to draw definitive conclusions on the impact of any type of PD on experiences of stigma. Also, our Axis I control group does not include the whole range of mental disorders. Our study does not exclude the possibility that some categories of Axis I disorders might experience levels of stigma comparable to PDs.

Based upon these findings, we believe therapists should be aware of psychiatric stigma when treating these subgroups of adolescents with personality problems and discuss its existence with their patients and families. Psychoeducation about the nature and etiology of PDs and treatment prognosis could be helpful interventions too. However, more research is needed to determine whether a clinical diagnosis might exacerbate existing stigma ${ }^{49}$ or if it might provide a framework to understand a range of interpersonal and self-impairments, contributing to the lessening of this devastating stigma.

\section{Author contributions}

$\mathrm{KC}$ designed the study, collected the data, and drafted the article. JH, DS, and DF participated in the design of the study and the revision of the final paper. DF performed statistical analysis and interpreted the results. BS participated in the design of the study, supervised the entire research project, and revised the paper critically. All authors read and approved the final manuscript.

\section{Disclosure}

The authors report no conflicts of interest in this work.

\section{References}

1. Hinshaw SP. The stigmatization of mental illness in children and parents: developmental issues, family concerns, and research needs. $J$ Child Psychol Psychiatry. 2005;46(7):714-734.

2. Mukolo A, Heflinger CA, Wallston KA. The stigma of childhood mental disorders: a conceptual framework. J Am Acad Child Adolesc Psychiatry. 2010;49(2):92-103; quiz 198.

3. Mukolo A, Heflinger CA. Factors associated with attributions about child health conditions and social distance preference. Community Ment Health J. 2011;47(3):286-299.

4. Farrington DP. The effects of public labelling. Br J Crimin. 1977;17: $112-125$.

5. Holguin G, Hansen DJ. The "sexually abused child": potential mechanisms of adverse influences of such a label. Aggress Violent Beh. 2003;8:645-670.

6. Pescosolido BA. Culture, children, and mental health treatment: special section on the national stigma study-children. Psychiatr Serv. 2007;58(6):611-612.

7. Perry BL, Pescosolido BA, Martin JK, McLeod JD, Jensen PS. Comparison of public attributions, attitudes, and stigma in regard to depression among children and adults. Psychiatr Serv. 2007;58(5):632-635.

8. Martin JK, Pescosolido BA, Olafsdottir S, McLeod JD. The construction of fear: Americans' preferences for social distance from children and adolescents with mental health problems. $J$ Health Soc Behav. 2007; 48(1):50-67.
9. Phelan JC. Geneticization of deviant behavior and consequences for stigma: the case of mental illness. J Health Soc Behav. 2005;46(4): 307-322.

10. Norvilitis JM, Scime M, Lee JS. Courtesy stigma in mothers of children with Attention-Deficit/Hyperactivity Disorder: a preliminary investigation. J Atten Disord. 2002;6(2):61-68.

11. Klasen H. A name, what's in a name? The medicalization of hyperactivity, revisited. Harv Rev Psychiatry. 2000;7(6):339-344.

12. Corrigan PW, editor. On the Stigma of Mental Illness: Practical Strategies for Research and Social Change. Washington, DC: American Psychological Association Press; 2005.

13. Yap MB, Wright A, Jorm AF. The influence of stigma on young people's help-seeking intentions and beliefs about the helpfulness of various sources of help. Soc Psychiatry Psychiatr Epidemiol. 2011;46(12): 1257-1265.

14. Moses T. Self-labelling and its effects among adolescents diagnosed with mental disorders. Soc Sci Med. 2009;68(3):570-578.

15. Calear AL, Griffiths KM, Christensen H. Personal and perceived depression stigma in Australian adolescents: magnitude and predictors. J Affect Disord. 2011;129(1-3):104-108.

16. Moses T. Stigma apprehension among adolescents discharged from brief psychiatric hospitalization. J Nerv Ment Dis. 2011;199(10):778-789.

17. Link BG, Phelan JC. Labeling and stigma. In: Scheid TL, Brown TN, editors. A Handbook for the Study of Mental Health: Social Contexts, Theories and Systems. 2nd Ed. New York, NY: Cambridge University Press; 2009:571-587.

18. Corrigan PW, Lurie BD, Goldman HH, Slopen N, Medasani K, Phelan S. How adolescents perceive the stigma of mental illness and alcohol abuse. Psychiatr Serv. 2005;56(5):544-550.

19. Jorm AF, Wright A. Influences on young people's stigmatising attitudes towards peers with mental disorders: national survey of young Australians and their parents. Br J Psychiatry. 2008;192(2):144-149.

20. Corrigan PW, Watson AC, Otey E, et al. How do children stigmatize people with mental illness? J Appl Soc Psychol. 2007;37(7):1405-1417.

21. McKeague L, Hennessy E, O'Driscoll C, Heary C. Peer Mental Health Stigmatization Scale: psychometric properties of a questionnaire for children and adolescents [published online ahead of print February 15, 2015]. Child and Adolescent Mental Health. 2015. doi.org/10.1111/ camh.12088.

22. Armitage CJ, Conner M. Efficacy of the Theory of Planned Behaviour: a meta-analytic review. Br J Soc Psychol. 2001;40(Pt 4):471-499.

23. Eisenberg D, Downs MF, Golberstein E, Zivin K. Stigma and help seeking for mental health among college students. Med Care Res Rev. 2009; 66(5):522-541.

24. Feenstra DJ, Busschbach JJ, Verheul R, Hutsebaut J. Prevalence and comorbidity of axis I and axis II disorders among treatment refractory adolescents admitted for specialized psychotherapy. J Pers Disord. 2011;25(6):842-850.

25. Westen D, Shedler J, Durrett C, Glass S, Martens A. Personality diagnoses in adolescence: DSM-IV axis II diagnoses and an empirically derived alternative. Am J Psychiatry. 2003;160(5):952-966.

26. Feenstra D, Hutsebaut J. Feenstra DJ, Hutsebaut J. [The prevalence, burden, structure and treatment of personality disorders in adolescents]. Tijdschr Psychiatr. 2014;56(5):319-325. Dutch.

27. Feenstra DJ, Hutsebaut J, Laurenssen EM, Verheul R, Busschbach JJ, Soeteman DI. The burden of disease among adolescents with personality pathology: quality of life and costs. J Pers Disord. 2012;26(4): 593-604.

28. Laurenssen EM, Hutsebaut J, Feenstra DJ, Van Busschbach JJ, Luyten P. Diagnosis of personality disorders in adolescents: a study among psychologists. Child Adolesc Psychiatry Ment Health. 2013;7(1):3.

29. Magallón-Neri E, Forns M, Canalda G, De la Fuente JE. Stigmatization, personality disorders and adolescence. Eur Psychiat. 2013; 28(Suppl 1):1.

30. Chanen AM, McCutcheon LK. Personality disorder in adolescence: the diagnosis that dare not speak its name. Pers Ment Health. 2008;2(1):35-41. 
31. Bender DS, Morey LC, Skodol AE. Toward a model for assessing level of personality functioning in DSM-5, part I: a review of theory and methods. J Pers Assess. 2011;93(4):332-346.

32. Silverman WK, Albano AM. The Anxiety Disorders Interview Schedule for DSM-IV-Child and Parent Versions. San Antonio, TX: Psychological Corporation; 1996.

33. Siebelink BM, Treffers PDA. Anxiety Disorders Interview Schedule for DSM-IV Child Version, Child Interview Schedule. Lisse, The Netherlands: Swets and Zeitlinger BV; 2001.

34. First M, Spitzer R, Gibbon M, Williams JBW. Structured Clinical Interview for DSM-IV Axis I Disorders (SCID I). New York, NY: New York State Psychiatric Institute; 1995.

35. Van Groenestijn MAC, Akkerhuis GW, Kupka RW, Schneider N, Nolen WA. [SCID-I: Structured Clinical Interview for Determination of DSM-IV Disorders]. Amsterdam: Harcourt Assessment; 1998. Dutch.

36. First MB, Spitzer R, Gibbon M, Williams J, Benjamin L. Structured Clinical Interview for DSM-IV Axis II Personality Disorders (SCID II). Washington, DC: American Psychiatric Press; 1997.

37. Weertman A, Arntz A, Kerkhofs M. [SCID II: Structured Clinical Interview for DSM-IV]. Amsterdam: Harcourt Assessment; 2000. Dutch.

38. American Psychiatric Association. Diagnostic and Statistical Manual of Mental Disorders, Text Revision. 4th ed. Arlington, VA: American Psychiatric Publishing; 2000.

39. Maffei C, Fossati A, Agostoni I, et al. Interrater reliability and internal consistency of the structured clinical interview for DSM-IV axis II personality disorders (SCID-II), version 2.0. J Pers Disord. 1997;11(3):279-284.

40. Weertman A, Arntz A, Dreessen L, van Velzen C, Vertommen S. Short-interval test-retest interrater reliability of the Dutch version of the Structured Clinical Interview for DSM-IV personality disorders (SCID-II). J Pers Disord. 2003;17(6):562-567.
41. Tromp NB, Koot HM. Dimensions of normal and abnormal personality: elucidating DSM-IV personality disorder symptoms in adolescents. J Pers. 2010;78(3):839-864.

42. Watson AC, Otey E, Westbrook AL, et al. Changing middle schoolers' attitudes about mental illness through education. Schizophr Bull. 2004;30(3):563-572.

43. Pinto MD, Hickman R, Logsdon MC, Burant C. Psychometric evaluation of the revised attribution questionnaire (r-AQ) to measure mental illness stigma in adolescents. J Nurs Meas. 2012;20(1):47-58.

44. Pinfold V, Toulmin H, Thornicroft G, Huxley P, Farmer P, Graham T. Reducing psychiatric stigma and discrimination: evaluation of educational interventions in UK secondary schools. Br J Psychiatry. 2003;182: 342-346.

45. Schulze B, Richter-Werling M, Matschinger H, Angermeyer MC. Crazy? So what! Effects of a school project on students' attitudes towards people with schizophrenia. Acta Psychiatr Scand. 2003;107(2):142-150.

46. Pinel EC. Stigma consciousness: the psychological legacy of social stereotypes. J Pers Soc Psychol. 1999;76(1):114-128.

47. Link BG, Cullen FT, Frank J, Wozniak JF. The social rejection of former mental patients: understanding why labels matter. Am J Soc. 1987;92(6):1461-1500.

48. Corrigan PW, Rafacz J, Rüsch N. Examining a progressive model of self-stigma and its impact on people with serious mental illness. Psychiatry Res. 2011;189(3):339-343.

49. Corrigan PW. How clinical diagnosis might exacerbate the stigma of mental illness. Soc Work. 2007;52(1):31-39.
Adolescent Health, Medicine and Therapeutics

\section{Publish your work in this journal}

Adolescent Health, Medicine and Therapeutics is an international, peer-reviewed, open access journal focusing on health, pathology, and treatment issues specific to the adolescent age group. All aspects of health maintenance, preventative measures and disease treatmen interventions are addressed within the journal and practitioners from

\section{Dovepress}

all disciplines are invited to submit their work as well as healthcare researchers and patient support groups.. The manuscript management system is completely online and includes a very quick and fair peerreview system. Visit http://www.dovepress.com/testimonials.php to read real quotes from published authors. 